\author{
Sambor Grucza \\ Instytut Komunikacji Specjalistycznej \\ i Interkulturowej \\ Uniwersytet Warszawski \\ sambor.grucza@uw.edu.pl
}

\title{
LINGWISTYCZNE PODSTAWY BADAŃ SPECJALISTYCZNEJ KOMUNIKACJI MIĘDZYKULTUROWEJ
}

1.

Przez dłuższy czas zajmowano się językami specjalistycznymi w taki sposób, jak gdyby komponentalnie ograniczały się do składu specyficznych wyrażeń określanych mianem „terminów”. W pewnym momencie zauważono jednak, że języki te należy traktować z funkcjonalnego punktu widzenia jako swego rodzaju językowe całości zawierające komponent fonemiczny, grafemiczny, morfologiczny, leksykalny, terminologiczny, gramatyczny oraz tekstemiczny, czyli tak, jakby były „całymi” i „autonomicznymi” językami, a nie tylko składami terminologicznymi. Stało się tak, ponieważ dostrzeżono, że komunikacja specjalistyczna odbywa się dzięki „całym” językom, a nie tylko dzięki pewnym ich komponentom. W konsekwencji języki specjalistyczne zaczęto badać z punktu widzenia spełniania przez nie funkcji komunikacyjnych w obrębie odnośnych wspólnot specjalistów i, niestety, tylko w taki sposób, jak gdyby ich rola polegała wyłącznie na spełnianiu wspomnianych funkcji. Zarazem zaczęto traktować je jako narzędzia komunikacji specjalistycznej. Dopiero później zauważono, że języki specjalistyczne spełniają także funkcje kognitywne, tj. takie, dzięki którym możliwe jest wytwarzanie, porządkowanie i utrwalanie wiedzy specjalistycznej (Jahr 1996; Knobloch, Schäder 1996; Engberg 2002, 2007; Engberg, Janich 2007; Faber 2012; Grucza S. 2013b; Grygiel 2017; Pelikan, Roelcke, Weber 2019; Pelikan, Roelcke, Weber 2020). 
W kolejnych częściach artykułu podejmę próbę naszkicowania lingwistycznych podstaw badań specjalistycznej komunikacji międzykulturowej, jakie proponuje antropocentryczna komunikologia (Grucza F. 2012), stanowiąca rozwinięcie antropocentrycznej teorii języków ludzkich (Grucza S. 2017).

\section{2.}

Czym różni się komunikacja specjalistyczna od komunikacji niespecjalistycznej? Po pierwsze, w akcie komunikacji specjalistycznej transferencji podlega wiedza specjalistyczna, a po drugie, transferencja ta odbywa się w oparciu o szczególne obiekty sygnałowe, tj. teksty specjalistyczne. Ostatecznie różnica między komunikacją specjalistyczną i niespecjalistyczną polega na tym, że udział w tej pierwszej biorą osoby, które posiadają odpowiednią: (a) wiedzę specjalistyczną oraz (b) odpowiednią kompetencję specjalistyczną, czyli taką kompetencję, która umożliwia im wykonywanie jakiegoś rodzaju specjalistycznej pracy, ponadto zaś posiadają (c) wiedzę o tym, co robią, czego ich praca dotyczy oraz (d) potrafią wypowiadać się o tym, co robią, jak wykonują swą pracę, a także umieją mówić o jej rezultatach (Grucza F. 1994; Kalverkämper 1998; Schubert 2007; Roelcke 2020).

Zakres kompetencji, na podstawie której możliwa jest językowa transferencja wiedzy specjalistycznej (tak po stronie nadawcy, jak obiorcy) można określić mianem specjalistycznej kompetencji komunikacyjnej. W jej obrębie wyróżnić można takie współczynniki jak: (a) specjalistyczną kompetencję językową, (b) specjalistyczną kompetencję dyskursywną, (c) specjalistyczną kompetencję kulturową oraz (d) specjalistyczną kompetencję międzykulturową (interkulturową), czyli takie umiejętności, które umożliwiają specjaliście komunikacyjne „przełączanie się” między różnymi kulturami.

Ramy specjalistycznej kompetencji językowej zależą od tego, czy wąsko, czy też szeroko wyznaczymy zakres tego, co uznajemy za język specjalistyczny, a ten można określić tak, że obejmie on: (a) tylko struktury wyrażeniowe lub (b) struktury wyrażeniowe powiązane ze znaczeniem, bądź (c) struktury wyrażeniowe powiązane ze znaczeniem i regułami komunikacyjnymi (pragmatycznymi) (Grucza F. 1983: 330). Niezależnie od tego, jak ujmiemy zakres specjalistycznej kompetencji językowej, trzeba w każdym przypadku wyróżnić w jej obrębie umiejętności formacyjne (generatywne) oraz funkcyjne. Oznacza to, że specjalistyczna kompetencja formacyjna w najwęższym rozumieniu języków specjalistycznych to umiejętności tworzenia wyrazów specjalistycznych (terminów), a specjalistyczna kompetencja funkcyjna to umiejętność posługiwania się nimi w funkcji znakowej. W szerszym rozumieniu języków specjalistycznych 
specjalistyczna kompetencja formacyjna obejmuje umiejętności tworzenia zdań, a specjalistyczna kompetencja funkcyjna - umiejętność posługiwania się nimi. W najszerszym rozumieniu języków specjalistycznych specjalistyczna kompetencja formacyjna obejmuje umiejętności tworzenia tekstów, a specjalistyczna kompetencja funkcyjna - umiejętność posługiwania się nimi, czyli wyrażania za ich pomocą wiedzy specjalistycznej (Grucza S. 2013b).

Specjalistyczna kompetencja dyskursywna to, najogólniej rzecz ujmując, umiejętności pozwalające specjalistom uczestniczyć w interakcji specjalistycznej, czyli prowadzić dialog, dyskusję, polemikę, których przedmiotem jest wiedza specjalistyczna. Oznacza to, że w obrębie specjalistycznej kompetencji dyskursywnej należy wyróżnić najpierw umiejętności prowadzenia dyskursu za pomocą tekstów zrealizowanych $\mathrm{w}$ formie graficznej lub taktylnej (potocznie nazywanych tekstami pisanymi), czyli tekstową kompetencję dyskursywną oraz umiejętności prowadzenia dyskursu za pomocą tekstów zrealizowanych $\mathrm{w}$ formie audialnej (potocznie nazywanych tekstami mówionymi), czyli mowną kompetencję dyskursywną, a także umiejętności prowadzenia dyskursu za pomocą tekstów zrealizowanych w formie migowej (które nazwać można tekstami migowymi), czyli migową kompetencję dyskursywną.

Specjalistyczną kompetencję kulturową tworzą specyficzne umiejętności wytworzone przez specjalistę (specjalistów) na potrzeby danego rodzaju komunikacji specjalistycznej prowadzonej w obrębie określonych wspólnot specjalistów. Umiejętności te dotyczą stylów tworzenia wiedzy specjalistycznej oraz jej językowego (tekstowego) wyrażania, a także stylów prowadzenia określonych specjalistycznych dyskursów. Specyfika danej specjalistycznej kompetencji kulturowej może być pochodną specyfiki kultury etnowspólnoty bądź specyfiki kultury danej wspólnoty specjalistów. Zauważyć trzeba, że dwie wspólnoty specjalistów, których członkowie należą do różnych etnowspólnot, ale do tej samej wspólnoty branżowej, mogą - ale niekoniecznie muszą - różnić się swoimi komunikacyjnymi kulturami. Oznacza to, że specjalistyczne kompetencje kulturowe umożliwiające członkom takich wspólnot komunikację specjalistyczną mogą, ale niekoniecznie muszą być różne.

Specjalistyczna kompetencja międzykulturowa (nazywana też interkulturową) to, po pierwsze, umiejętność „przełączania się” między paralelnymi specjalistycznymi kulturami, będącymi elementami różnych etnokultur, po drugie zaś, umiejętność „przełączania się” między różnymi branżowymi, dziedzinowymi czy korporacyjnymi kulturami specjalistycznymi, będącymi elementami tej samej etnokultury.

Dodać trzeba, że wielokulturowość (multikulturowość) to nie to samo, co międzykulturowość (interkulturowość). Czym innymi jest bycie w posiadaniu dwóch lub więcej kultur (bycie wielokulturowym), czyli posiadanie więcej niż 
jednej kompetencji kulturowej, a czym innym umiejętność „przełączania się” między tymi kulturami, czyli posiadanie kompetencji międzykulturowej (interkulturowej).

Z uwag poczynionych w tej części wynika także, że specjalistyczna kompetencja kulturowa implikuje specjalistyczną kompetencję dyskursywną, a specjalistyczna kompetencja dyskursywna implikuje odpowiednią specjalistyczną kompetencję językową.

\section{3.}

W badaniach komunikacji specjalistycznej, w tym oczywiście także specjalistycznej komunikacji międzykulturowej, trzeba koniecznie dokonać jeszcze ontologicznej dyferencjacji tego, do czego odnoszą się wyrażenia: „język specjalistyczny”, „wiedza specjalistyczna” i „kultura specjalistyczna”. Z ontologicznego punktu widzenia rzeczy, do których się odnoszą trzeba podzielić na trzy kategorie (Grucza S. 2013b):

a) rzeczywiste języki ${ }^{1}$ specjalistyczne, czyli języki specjalistyczne konkretnych osób, tzw. idiolekty specjalistyczne; rzeczywiste wiedze specjalistyczne, tj. wiedze konkretnych osób, czyli idiowiedze specjalistyczne; rzeczywiste kultury specjalistyczne, czyli kultury specjalistyczne konkretnych osób, tj. idiokultury specjalistyczne;

b) przekroje bądź sumy logiczne idiolektów specjalistycznych, idiowiedz specjalistycznych, idiokultur specjalistycznych osób wziętych pod uwagę, czyli odpowiednio polilekty specjalistyczne, poliwiedze specjalistyczne, polikultury specjalistyczne;

c) modele konkretnych polilektów specjalistycznych, poliwiedz specjalistycznych, polikultur specjalistycznych, które określa się przykładowo jako „polski język specjalistyczny medycyny”, „wiedza medyczna”, „kultura medyczna”. Modele te to intelektualne konstrukty odwzorowujące w mniejszym lub większym stopniu albo idolekt, idiowiedzę, idiokulturę jakiegoś konkretnego specjalisty, albo polilekt, poliwiedzę, polikulturę jakiegoś zbioru wziętych pod uwagę specjalistów.

$\mathrm{Z}$ powyższych ustaleń wynika, że zarówno punktem wyjścia, jak i punktem ostatecznego odniesienia rozważań oraz badań specjalistycznej komunikacji międzykulturowej są rzeczywiste języki specjalistyczne, rzeczywiste wiedze specjalistyczne oraz rzeczywiste kultury specjalistyczne konkretnych specjalistów, czyli idiolekty specjalistyczne, idiowiedze specjalistyczne i idiokultury specjalistyczne.

\footnotetext{
1 Wyrażenia ,język” używam tu w znaczeniu „język ludzki”.
} 
4.

Jak wspomniałem, kultura (idiokultura), a tym samym także kultura specjalistyczna (idiokultura specjalistyczna), to pewne umiejętności (wiedza i sprawności) wytworzone przez człowieka (specjalistę), którymi kieruje się on w swoim działaniu, widzeniu świata, w swojej pracy, twórczości itd. (Suchodolski 1982; Kłoskowska 1983; Labuda 1985; Grucza F. 1989, 1992, 2012; Suchodolski, Wojnar 1990).

Języki specjalistyczne (idiolekty specjalistyczne) i kultury specjalistyczne (idiokultury specjalistyczne) należy badać tak, jak gdyby były kulturami autonomicznymi, pełnymi, mimo tego, że w sensie ontologicznym takimi nie są, ponieważ każdy idiolekt specjalistyczny jest powiązany z idiolektem ogólnym, a każda idiokultura specjalistyczna jest $\mathrm{w}$ jakimś stopniu połączona nie tylko $\mathrm{z}$ idiokulturą ogólną, lecz również z inną idiokulturą specjalistyczną. Poszczególnych kultur specjalistycznych nie można w żadnym razie traktować jako wariantów idiokultury ogólnej. Podobnie sprawa ma się z językami specjalistycznymi - nie są one wariantami języka ogólnego.

Stopień pokrywania się zakresu danej kultury specjalistycznej z zakresem odnośnej kultury ogólnej oraz innych kultur specjalistycznych jest względny, ponieważ - po pierwsze - różnie można wyznaczyć zakres rzeczywistości nazywany za pomocą wyrażenia „kultura”, i - po drugie - także różnie można wyznaczyć zakres rzeczywistości nazywany za pomocą wyrażeń „kultura ogólna” i „kultura specjalistyczna”. Stopień pokrywania się zakresu danej kultury specjalistycznej z zakresem odnośnej kultury ogólnej oraz zakresami innych kultur specjalistycznych zależy także od tego, w jakim stopniu członkowie danej wspólnoty specjalistów wytworzyli specjalistyczne formy kulturowe w obrębie swojej wspólnoty, następnie od tego, w jakim stopniu członkowie odnośnej wspólnoty etnokulturowej rozwinęli swoją kulturę ogólną oraz - ostatecznie - od tego, w jakim stopniu członkowie innych wspólnot specjalistów wytworzyli specjalistyczne formy kulturowe w obrębie swoich wspólnot.

Ponadto wszystkie specjalistyczne umiejętności (wiedza i sprawności) kulturowe, tak jak każde inne umiejętności, mają charakter gradualny, a w związku $\mathrm{z}$ tym granicy między kulturą specjalistyczną (idiokulturą specjalistyczną) a kulturą ogólną (idiokulturą ogólną) oraz granicy między innymi kulturami specjalistycznymi (idiokulturami specjalistycznymi) nie należy traktować jako granicy ostrej.

Na gruncie przedstawionej powyżej ontologicznej charakterystyki rzeczywistości określanej za pomocą wyrażenia „specjalistyczna kompetencja kulturowa” stwierdzić trzeba, że pojęcie „specjalistycznej kompetencji kulturowej” implikuje pojęcie „specjalistycznej kompetencji językowej”. Inaczej mówiąc, 
zakres rzeczywistości określanej za pomocą wrażenia „idiolektalna kompetencja specjalistyczna” jest częścią zakresu rzeczywistości określanej za pomocą wyrażenia „idiokulturowa kompetencja specjalistyczna”.

Wszystkie ontologiczne uwagi, jakie poczyniłem wyżej w odniesieniu do zakresów znaczeniowych wyrażenia „specjalistyczna kompetencja kulturowa” można przez analogię odnieść do zakresów znaczeniowych wyrażenia „specjalistyczna kompetencja międzykulturowa”. Oznacza to, że na gruncie przyjętej tu koncepcji antropocentrycznej, pojęcie „specjalistycznej kompetencji międzykulturowej” implikuje „pojęcie specjalistycznej kompetencji kulturowej”. Innymi słowy, specjalistyczna kompetencja kulturowa jest częścią specjalistycznej kompetencji międzykulturowej.

\section{5.}

Warto zaznaczyć, że żaden język, a więc także żaden język specjalistyczny, nie jest, ponieważ być nie może, narzędziem żadnej komunikacji. Jeżeli jednak w odniesieniu do komunikacji językowej użyjemy wyrażenia „narzędzie”, to za narzędzia komunikacji (specjalistycznej) uznać można wyłącznie teksty/ wypowiedzi (specjalistyczne), a nie języki (specjalistyczne), bowiem to one, a nie języki (specjalistyczne) mają postacie sygnałowe i jako takie mogą pełnić funkcję zastępników znaczeń nadanych im przez ich twórców. Nie ma przy tym znaczenia, czy mówimy o płaszczyźnie denotatów, czy też o płaszczyźnie desygnatów, dlatego że ani jednych, ani drugich nie można traktować jako obiektów zawierających się (w dosłownym sensie tego wyrazu) w tekstach (specjalistycznych) - trzeba je raczej postrzegać jako wartości przypisywane im przez ich twórców i odbiorców.

$\mathrm{W}$ takim rozumieniu teksty specjalistyczne to językowe eksponenty wiedzy specjalistycznej i tylko w takim znaczeniu można określać je mianem „narzędzi”. Teksty specjalistyczne są tworami językowymi, obiektami wytworzonymi „za pomocą" (jakiegoś) języka specjalistycznego. Jest rzeczą oczywistą, że języki specjalistyczne jako „narzędzie” tworzenia tekstów specjalistycznych nie są „narzędziami” komunikacji specjalistycznej, tak jak umiejętności, za pomocą których wytworzono narzędzie do grabienia liści nie są narzędziem do grabienia liści (Grucza F. 1993; Grucza S. 2013a).

Dodam jeszcze, że transferencja wiedzy specjalistycznej nie polega na przekazywaniu jej, bowiem żadnej wiedzy nie można nikomu przekazać. Nadawca może przekazać odbiorcy jedynie pewien obiekt sygnałowy, np. tekst specjalistyczny, któremu przyporządkował (w swoim mózgu) określoną treść znaczeniową, tj. określoną wiedzę specjalistyczną. Odbiorca 
odbiera ten obiekt sygnałowy i dzięki niemu wytwarza w swoim mózgu określoną treść znaczeniową, tj. określoną wiedzę specjalistyczną. W mózgu nadawcy następuje zatem przyporządkowanie określonym treściom znaczeniowym określonych obiektów sygnałowych, a w mózgu odbiorcy przyporządkowanie określonym obiektom sygnałowym określonych treści znaczeniowych. Relacja pomiędzy obiektem sygnałowym a treścią znaczeniową, do której ten obiekt się odnosi, ma oczywiście charakter konwencjonalny.
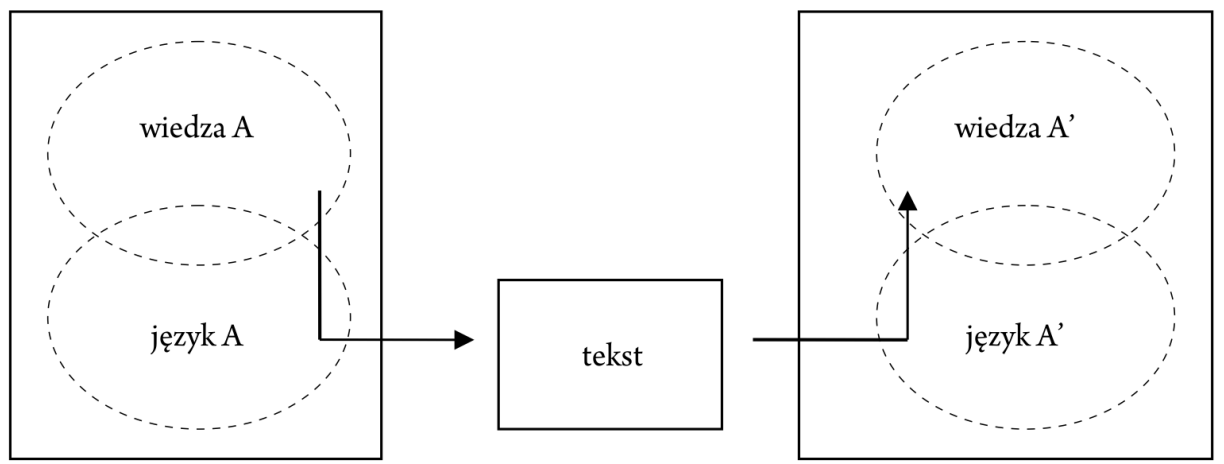

Rysunek 1. Wyrażanie i rekonstruowanie wiedzy

Komunikacja specjalistyczna polega zatem na wytwarzaniu obiektów sygnałowych będących zastępnikami wiedzy specjalistycznej, odbieraniu ich i tworzeniu na podstawie tych obiektów sygnałowych wiedzy specjalistycznej. W tym zakresie komunikacja specjalistyczna niczym nie różni się od komunikacji niespecjalistycznej.

Języki specjalistyczne spełniają zarówno funkcje komunikacyjne, tj. służą do transferowania (komunikowania, „przekazywania”) wiedzy specjalistycznej, jak i funkcje kognitywne, czyli służą do wytwarzania, porządkowania i utrwalania wiedzy specjalistycznej, przy czym funkcja kognitywna jest podstawowa. Stwierdzić trzeba ponadto, że to nie języki specjalistyczne (same z siebie) wiedzę specjalistyczną wytwarzają, porządkują, utrwalają i transferują, lecz ludzie - specjaliści posługujący się tymi językami. Ostatecznie trzeba powiedzieć, że celem komunikacji specjalistycznej jest transferencja wiedzy specjalistycznej.

\section{6.}

Instytucjonalizacja akademickich badań komunikacji specjalistycznej w Polsce sięga przełomu lat osiemdziesiątych i dziewięćdziesiątych XX wieku i wiąże się z pracami badawczymi prowadzonymi w Instytucie Lingwistyki 
Stosowanej Uniwersytetu Warszawskiego ${ }^{2}$. Pierwszym akademickim ośrodkiem w Polsce, w którym prowadzono systematyczne badania nad komunikacją specjalistyczną była założona w 2000 roku na Uniwersytecie Warszawskim Katedra Języków Specjalistycznych, przekształcona później w dzisiejszy Instytut Komunikacji Specjalistycznej i Interkulturowej ${ }^{3}$. W jego ramach działają obecnie cztery centra badawcze, które zajmują się szczegółowymi rodzajami specjalistycznej komunikacji (międzykulturowej) $)^{4}$ : Research Center for Business Communication Audit ${ }^{5}$, Business Communication Research Center ${ }^{6}$, Aviation Communication Research Centre ${ }^{7}$, International Legal Communication Research Center ${ }^{8}$. Badania specjalistycznej komunikacji międzykulturowej prowadzi także założona dzięki staraniom prof. Stanisława Goździa-Roszkowskiego Katedra Języków Specjalistycznych oraz Komunikacji Międzykulturowej Uniwersytetu Łódzkiego9. Badania takie prowadzone są ponadto w Zakładzie Języków Specjalistycznych Instytutu Filologii Angielskiej Uniwersytetu Rzeszowskiego oraz w kilku innych ośrodkach akademickich. Nie zostały one jednak jeszcze zinstytucjonalizowane w taki sposób, jak ma to miejsce w przypadku wymienionych wyżej jednostek.

\section{Bibliografia}

Engberg J. (2002), Fachsprachlichkeit - eine Frage des Wissens, [w:] Ch. Schmidt (red.), Wirtschaftsalltag und Interkulturalität. Fachkommunikation als interdisziplinäre Herausforderung, Wiesbaden, s. 219-238.

Engberg J. (2007), Wie und warum sollte die Fachkommunikationsfroschung in Richtung Wissenstrukturen erweitert werden?, „Fachsprache. International Journal of LSP", z. 3-4, s. 2-25.

Engberg J., Janich N. (2007), Über die Komplexität fachkomunikativer Sprachkompetenz und ihre Beschreibung, [w:] D. Heller, K. Ehlich (red.), Studien zur Rechtskommunikation, Bern, s. 209-234.

\footnotetext{
2 Wyniki pierwszych badań przedstawiono w Grucza, Kozłowska 1994.

3 Zob. http://www.iksi.uw.edu.pl (dostęp: 26.07.2020).

$4 \mathrm{Na}$ ich stronach zamieszczona została obszerna literatura przedmiotu.

5 Zob. http://rc-bca.iksi.uw.edu.pl (dostęp: 26.07.2020).

6 Zob. http://bcrc.iksi.uw.edu.pl (dostęp: 26.07.2020).

7 Zob. http://acrc.iksi.uw.edu.pl (dostęp: 26.07.2020).

8 Zob. http://legal-communication.iksi.uw.edu.pl (dostęp: 26.07.2020).

9 Zob.http://kjs.uni.lodz.pl/ (dostęp: 26.07.2020).
} 
Faber P. (red.) (2012), A Cognitive Linguistics View of Terminology and Specialized Languages, Berlin.

Grucza F. (1983), Zagadnienia metalingwistyki. Lingwistyka - jej przedmiot, lingwistyka stosowana, Warszawa [także w: Franciszek Grucza. Dzieła zebrane, t. 8, http://www.iksi.uw.edu.pl/documents/11738337/14640936/FG Tom_8.pdf (dostęp: 26.07.2020)].

Grucza F. (1989), Język a kultura, bilingwizm a bikulturyzm: lingwistyczne i glottodydaktyczne aspekty interlingwalnych i interkulturowych różnic i zbieżności, [w: ] F. Grucza (red.), Bilingwizm, bikulturyzm, implikacje glottodydaktyczne, Warszawa, s. 9-49 [także w: Franciszek Grucza. Dzieła zebrane, t. 4, http:// www.iksi.uw.edu.pl/documents/11738337/14640936/FG_Tom_4.pdf (dostęp: 26.07.2020)].

Grucza F. (1992), Kulturowe determinanty języka oraz komunikacji językowej, [w:] F. Grucza (red.), Język, kultura - kompetencja kulturowa, Warszawa, s. 9-70 [także w: Franciszek Grucza. Dzieła zebrane, t. 4, http://www.iksi.uw.edu.pl/ documents/11738337/14640936/FG_Tom_4.pdf(dostęp: 26.07.2020)].

Grucza F. (1993), Język, ludzkie właściwości językowe, językowa zdolność ludzi, [w: ] J. Piontka, A. Wiercińska (red.), Człowiek w perspektywie ujęć biokulturowych, Poznań, s. 151-174 [także w: Franciszek Grucza. Dzieła zebrane, t. 3, http://www.iksi.uw.edu.pl/documents/11738337/14640936/FG_ Tom_3.pdf (dostęp: 26.07.2020)].

Grucza F. (1994), O upowszechnianiu wiedzy naukowej i jego językowych wspótczynnikach, „Nauka”, nr 4, s. 31-55 [także w: Franciszek Grucza. Dzieła zebrane, t. 2, http://www.iksi.uw.edu.pl/documents/11738337/14640936/ FG_Tom_2.pdf (dostęp: 26.07.2020)].

Grucza $\overline{\mathrm{F}}$. (2012), Antropocentryczna a paradygmatyczna (tradycyjna) lingwistyka (stosowana) i kulturologia (stosowana), „Lingwistyka Stosowana/Applied Linguistics/Angewandte Linguistik", nr 6, s. 5-43, http://alp.uw.edu.pl/ wp-content/uploads/sites/315/2018/03/Lingwistyka-Stosowana-6_2012. pdf (dostęp: 26.07.2020).

Grucza F., Kozłowska Z. (red.) (1994), Języki specjalistyczne. Materiaty zXVII Ogólnopolskiego Sympozjum ILS UW, Warszawa 9-11 stycznia 1992, Warszawa.

Grucza S. (2013a), Od lingwistyki tekstu do lingwistyki tekstu specjalistycznego, Warszawa, wyd. 3, https://portal.uw.edu.pl/web/snikla/tomy-serii (dostęp: 26.07.2020).

Grucza S. (2013b), Lingwistyka języków specjalistycznych, Warszawa, wyd. 2, https://portal.uw.edu.pl/web/snikla/tomy-serii (dostęp: 26.07.2020).

Grucza S. (2017), Lingwistyka antropocentryczna, [w:] S. Grucza, M. Olpińska-Szkiełko, M. Płużyczka, I. Banasiak, M. Łączek, A. Bonek, A. Kaleta, A. Sztuk (red.), Franciszek Grucza, Dzieła zebrane, t. 1: O nauce prof. Franciszka Gruczy, Warszawa, s. 161-180. 
Grygiel M. (red.) (2017), Cognitive Approaches to Specialized Languages, Cambridge.

Jahr S. (1996), Das Verstehen von Fachtexten. Rezeption - Kognition - Applikation, Tübingen.

Kalverkämper H. (1998), Fach und Fachwissen, [w: ] L. Hoffmann, H. Kalverkämper, H.E. Wiegand (red.) Fachsprachen, t. 1, Berlin-New York, s. 1-24. Kłoskowska A. (1983), Socjologia kultury, Warszawa.

Knobloch C., Schaeder B. (red.) (1996), Nomination - fachsprachlich und gemeinsprachlich, Opladen.

Labuda G. (1985), Innowacje w nauce i kulturze, [w:] B. Suchodolski, J. Kubin (red.), Nauka w kulturze ogólnej, cz. I, Wrocław, s. 31-55.

Pelikan K., Roelcke Th., Weber T. (2020), Wissen - Information - Transformation. Umrisse der Transferwissenschaften, [w:] K. Pelikan, Th. Roelcke (red.), Information und Wissen - Beiträge zur transdisziplinären Diskussion, Berlin, s. $17-46$.

Roeckle Th. (2020), Fachsprachen, Berlin.

Schubert K. (2007), Wissen, Sprache, Medium, Arbeit. Ein integratives Modell der ein-und mehrsprachigen Fachkommunikation, Tübingen.

Suchodolski B. (1982), Edukacja kulturowa a egzystencja człowieka, „Życie Literackie", R. XXXII, nr 42.

Suchodolski B., Wojnar I. (1990), Kierunki i treści ogólnego kształcenia człowieka. Warszawa-Kraków.

Sambor Grucza

\section{LINGUISTIC FOUNDATIONS OF RESEARCH ON SPECIALIZED INTERCULTURAL COMMUNICATION}

(Summary)

The paper presents the linguistic foundations of research on intercultural specialized communication from the point of view of anthropocentric communicology. It must be assumed that in these studies, firstly, specialized intercultural communication is based on communication competence, within which one can distinguish (a) specialized language competence, (b) specialized discursive competence, (c) specialized cultural competence and (d) specialized intercultural competence. Secondly, it is necessary to distinguish between (i) specialized idiolects, specialized knowledges and specialized idiocultures, (ii) specialized polylects, specialized knowledges, and specialized polycultures, (iii) models of specialized languages, models of specialized knowledges, and models of specialized cultures. The paper discusses and develops these issues.

Key words: specialized intercultural communication, languages for specialized purposes, specialized competences, intercultural competences, specialized knowledge 